\title{
Animal Experiments in Dermatology
}

Nijmegen

Author's address: Prof. Dr. J. W. H. Mali, Sint Radboud Ziekenhuis, Javastraat 104, Nijmegen (Holland)

Discussion about the possibilities for dermatological research in animal experiments.

The advantages of pigs and hairless mice are stressed.

163rd Meeting Netherl. Soc. Derm., Nijmegen 1962. Dermatologica 125: 335 (1962)

Skin and Muscle Circulation in Dogs

By M. J. G. A. WAELEN, F. SONNEVILLE and A. J. M. BRAKKEE (Nijmegen)

A research on the drug action on the peripheral circulation was demonstrated.

As the organism is capable of regulating and varying blood flow in difFerent tissues, for instance skin and muscle separately, the assumption was made that various tissues have a different response to the drugs we used.

The drugs were administered intra-arterially in such a way that they influenced skin as well as muscle circulation. Flow velocity and oxygen saturation were examined simultaneously. The dose of drugs chosen was very small so that the circulation as a whole was not affected, that means that heart action and blood pressure remained constant.

For several drugs, then, a difference in action on skin and muscle circulation could be demonstrated.

Analysis of the effects on flow and oxygen saturation give indications for the method of using of several pharmaca.

Author’s address: Dr. M. J. G. A. Waelen, Dr. F. Sonneville and Dr. A. J. M. Brakkee, University Dept. of Pharmacology and Medical Physics, Nijmegen (Holland) 